\title{
The Design and Implementation of English Learning System in Open and Distance Education
}

\author{
Xiaodan Wang \\ International College of Tianjin Radio and TV University, Tianjin 300191, China \\ Wangxiaodan@gmail.com
}

Keywords: distance education, English learning, system design.

\begin{abstract}
Through the research on mobile learning and the status of related technologies, this paper proposes the design of mobile English learning system and analyzes its feasibility and implementation in open and distance education. The author firstly discusses the concept and technology of mobile learning and the development and application of mobile widget which integrates into web to provide learners with efficient learning environment. Then the theory analysis and demand analysis of mobile English learning system are conducted. On the basis of the pilot study, the design of the system is divided into four-layer structures and constructed by using Nokia Web Run-Time (WRT) platform technology upon mobile widgets. The function in the mobile terminal needs to be achieved by the main modules of online testing, video on demand, English translation and dialogue scenes. The Content Management System (CMS) server applies to Windows Apache + Mysql/MariaDB + Perl/PHP/Python (WAMP), by which establishes a database so that the mobile terminal within the application package can send a request to the server and return data through a Uniform Resource Locator (URL) path. The mobile English learning system, through the reasonable analysis and design, is easily accessed to the distance learners and realizes scalability, security and operational convenience.
\end{abstract}

\section{Introduction}

Distance education has existed in the world for over 150 years. Although China has only a short history of it, distance education has achieved great development since 1999, when the Ministry of Education in China started the pilot research on the Reform of Personnel Training Model and Open Education in China Central Radio and TV University (CCRTVU) [1]. With the continuous development of distance education, the concept of open and distance education appears. It applies advanced science and technology to teaching and learning and dedicates to realize the globalization of education. English as a major subject in open and distance education plays an important role in cultivating students' communicative competence to access to cutting-edge information in the world. Therefore, it is crucial to design an intensive English learning system to provide learners with more language practice opportunities to enhance their English language proficiency; while in the distance learning process, learners are required to skillfully use the system to find out specific language learning strategies.

\section{M-learning and Mobile Widget}

M-Learning has risen at the historic moment as the development of information technology and popularization along with wireless communication equipment [2]. It is one of the new learning forms of distance education accomplished by wireless technology and mobile computer equipments, such as handset, PDA, MPS as well as hand-hold E-book to gain the learning information, resources and services at anytime. Mobile learning has the characteristic of breaking through the limitations of learning time and space, which helps learners to get the maximum improvement of learning efficiency and meet the demand of their lifelong study. The appearance of $3 \mathrm{G}$ mobile communication technology has enormously promoted the integration of mobile communication and Internet to distance education. Flexibility and broad coverage are the main features of M-learning system under 
3G technologies, hence, it is easy for learners to go on study momentarily at any place. Meanwhile, 3G technology also brings brand-new field and enriches the functionality of M-learning. Wireless communication is shown in Fig. 1.

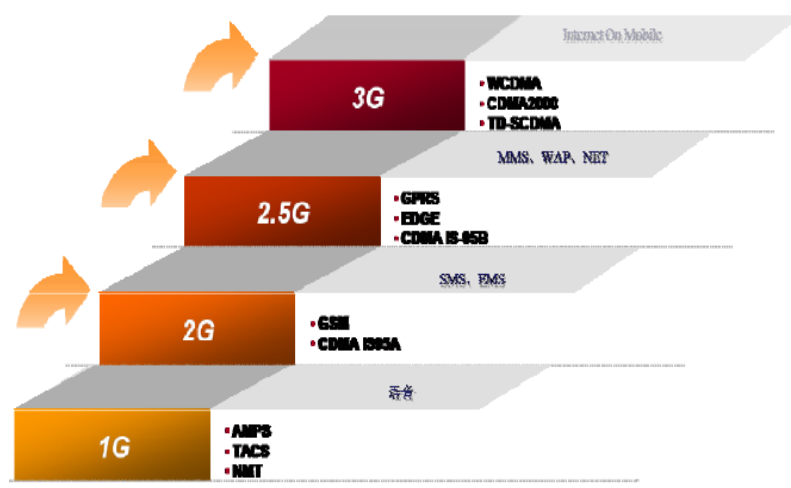

Fig. 1 Wireless communication

Widget service is a Jeb service and provided by S60 Web Runtime (WRT) environment. Widget service can run independently without the browser [3-5]. Furthermore, Widget is different from Web application. Web Widget has its own architecture and needs to be saved some specific components in the mobile terminal. Recently, Widget has several kinds, e.g. Vista Widget, Google Widget, Opera Widget, and Yahoo Widget and so on. Based on Web Widget, some researchers considered that the site owner could greatly improve the aid of the Widget user experience. In view of this, with the help of Widget, English learning system can be promoted to bring convenience to the distance learners.

\section{Theory Analysis}

Based on distance educational administration theory, the current researches indicate that distance learning, through the process of effective management, can provide learners with intensive learning support [6]. Learners, learning processes and learning management services are the three core elements of distance learning. On the basis of the intrinsic relationship among the three elements, a theoretical model of distance learning management-Learners Process Services (LPS) is proposed, as shown in Fig. 2.

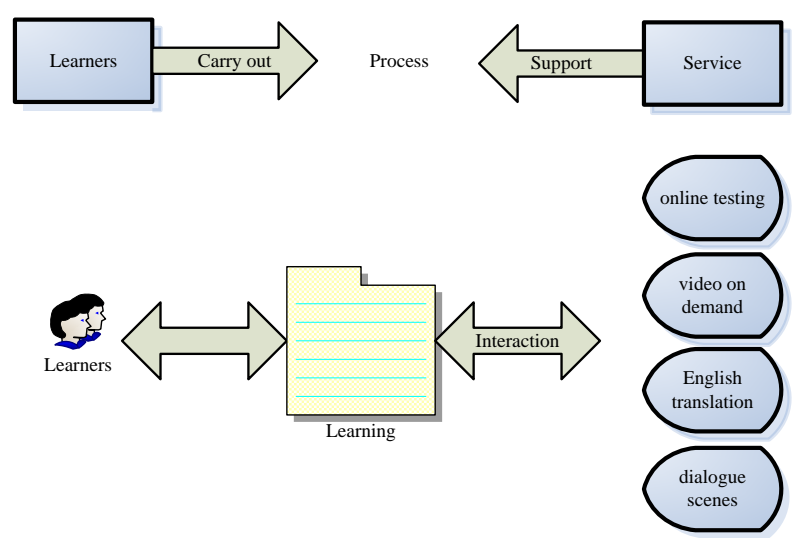

Fig. 2 Theory model of distance learning management

The model erects a bridge between the idea of distance learning service and the service-oriented architecture. It provides a theoretical guidance for the design and implementation of English learning system based on service-oriented architecture.

$$
s(k)=\frac{\beta_{0} \mu(k)+\beta_{1} n(k)+\beta_{2} p(k)}{\beta_{0}+\beta_{1}+\beta_{2}}
$$

$s(k)$ is decomposed into the product of three matrices.

$$
d(k)=\frac{\alpha c(k)+\varepsilon r(k)+\eta t(k)}{\alpha+\varepsilon+\eta}
$$


As can be seen from Eq. (1) and Eq. (2), the adaptive principle used in distance learning is analyzed. From Mario Cannataro \& Andrea Puglise's view, the following three factors are focused on: learning action, learning process and learning situation, defined as $\beta_{0}, \beta_{1}, \beta_{2}$, the membership is expressed as $\mathrm{u}$, $\mathrm{n}, \mathrm{p} . \mathrm{s}(\mathrm{k})$ referring to the degree of coupling with the three factors. The same tokens, $\alpha, \varepsilon, \eta$ relevantly express learning action, learning process and learning community, with $\mathrm{c}, \mathrm{r}, \mathrm{t}$ express the membership.

Besides, the foreign researches on mobile learning on the tag cloud are shown in Fig. 3. It shows any sort of learning that happens when a learner is not at a fixed, predetermined location, or when a learner takes advantage of the learning opportunities offered by mobile technologies.

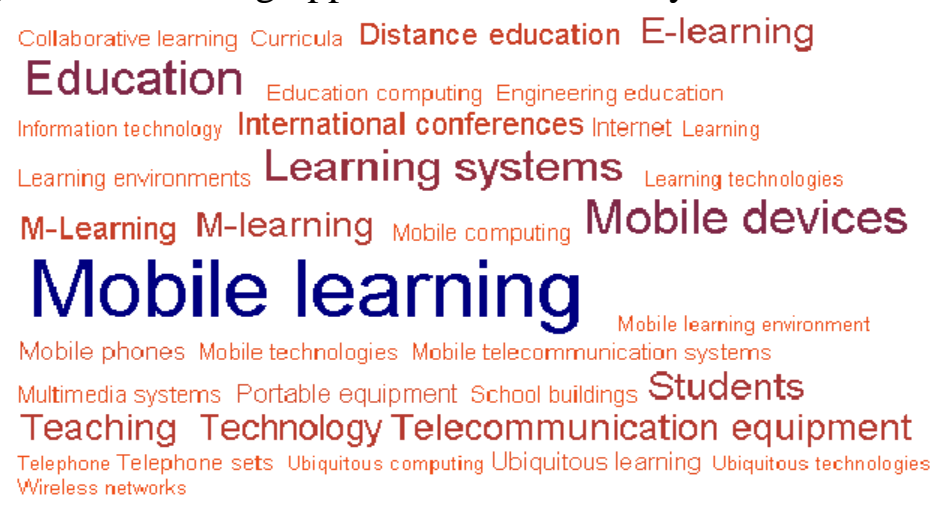

Fig. 3 Foreign researches on mobile learning on the tag cloud

\section{Demand Analysis of Distance Learners on Mobile English Learning System}

Distance learners are greatly interested in mobile learning. It broadens their horizon to conduct personalized learning via mobile learning system during English language learning process. Based on a large number of documents and tracking projects, the results show that a solid and effective research must be on the basis of knowing many of the requirements of the participants and explore specific system function, types of media and effective practice to meet the needs of certain groups. In view of this, the research is conducted by the way of combining theoretical with empirical evidence, supporting by the reference model of digital learning system which gives instructions to construct the mobile English learning system.

\section{The Design of Mobile English Leaning System}

The system mainly consists of four-layer structure including presentation layer, business logic layer, data layer and application layer. The development tools, development environment, and the use of the system are described below:

(1) The application server: Windows XP.

(2) The database: MySql;

(3) The main development language and technology: JavaScript, PHP, widget, AJAX and Code Igniter framework;

(4) Client for mobile phones using NOKIA S60 3rd Edition FP2 simulator.

Mobile English learning system adopts B/S/S four-layer model as the system architecture. Presentation layer is divided into two parts: background management system and mobile terminal system. The mobile client runs the application on the users' phone through Nokia S60 platform. When the users select the corresponding function through the phone shown in the interface, it is requested program processing from the inside of the package URL to the server of Content Management System (CMS). The phone installed on the English learning system encapsulates some business logic functions. Background management system is mainly related to the operation of the database server. The application layer is running on the server, which encapsulates the whole application request of the mobile client, the related business logic and the database operation. After the server accepts the users' instructions, it carries out the relevant business processing, while the 
results transfer the final format to the users' mobile phone which they can eventually handle what is shown on the phone screens. The operational process is: after the users get into the modules of online testing, video on demand, English translation and dialogue scenes, they select the corresponding type and then perform related operations. Taking the users selecting the module of video on demand as an example, the processing program of the server will find out all video directory names related with the data in the database and then returned and presented them to the client. Additionally, as shown in Fig. 4, Martin Weller proposed a variety of learning environments providing various distance learning resources for the benefit of the learners.

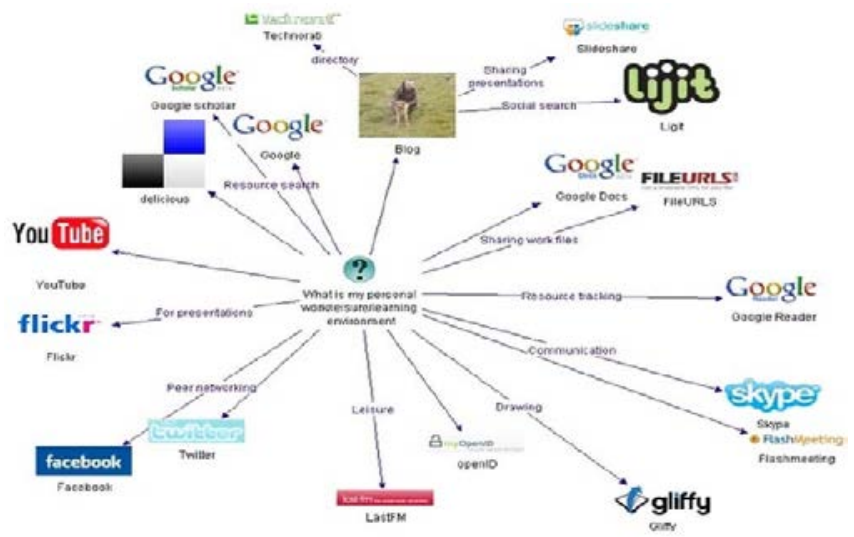

Fig. 4 Distance English learning environments

\section{Conclusion}

This article explains the concept of English learning system in open and distance education. The system is reasonably designed and implemented on S60 platform for the learners using their mobile phone to learn at any time and space. The featured function of the system is to create an efficient learning environment for distance learners. To a certain extent, it makes up for the shortcomings of distance English learning conducted by wired network. However, there is still much room for the improvement of the system. More researches should be done deeply on the following aspects: how to increase the system function from one-way to two-way communication, how to enhance the maintenance of the system and in what way to keep the users interacting with the system. The author expects that the preset study can provide relevant reference for the future researches.

\section{References}

[1] E.Bembridge, T. Levett-Jones, S.Y.-S. Jeong. The transferability of information and communication technology skills from university to the workplace: a qualitative descriptive study. Nurse Education Today, 2011, 31(3): 245-252.

[2] Mark van Harmelen. Personal Learning Environments. Proceedings of the Sixth International Conference on Advanced Learning Technologies (ICALT'06) IEEE Computer Society, 2006: 815-816.

[3] Information on http://www.docin.com/p-60054395.htm1.

[4] Wang ZhiMing. WRT Widget on S60. NOKIA, 2009.9: 56-59.

[5] JIA Keliangl, PANG Xiuling. Query Expansion Based on Semantics andStatistics in Chinese Question Answering System. Wuhan UniversityJournal of Natural Sciences, 2009, (06): 505-508.

[6] Deborah L.McGuinness. Question answering on the semanticWeb. IEEE Intelligent Systems, 2014, 19(1): 82-85. 